\title{
Effectiveness of MAID Therapy against Metastatic Malignant Phyllodes Tumors and Stromal Sarcoma of the Breast
}

\author{
Kan Yonemoria Chikako Shimizu ${ }^{a}$ Tadashi Hasegawa ${ }^{b}$ Koji Matsumoto ${ }^{a}$ Tsutomu Kouno $^{a}$ \\ Yasuhiro Yamanaka ${ }^{a}$ Masashi Ando ${ }^{a}$ Noriyuki Katsumata ${ }^{a}$ Yasuhiro Fujiwara ${ }^{a}$ \\ a Breast and Medical Oncology Division, National Cancer Center Hospital, \\ b Pathology Division, National Cancer Center Institute, Tokyo, Japan
}

Key Words

Chemotherapy · Phyllodes tumor, malignant · Metastasis

\section{Summary}

Background: Malignant phyllodes tumors and stromal sarcoma are rare malignancies of the breast. The efficacy of systemic chemotherapy against metastatic malignant phyllodes tumors and metastatic stromal sarcoma remains unknown. Patients and Methods: We retrospectively analyzed 8 patients with metastatic malignant phyllodes tumors or stromal sarcoma, who were treated with MAID (mesna, doxorubicin, ifosfamide, dacarbazine) chemotherapy. The MAID therapy was administered intravenously every 4 weeks as follows: mesna $1,500 \mathrm{mg} / \mathrm{m}^{2} /$ day, days $1-4$; doxorubicin $20 \mathrm{mg} / \mathrm{m}^{2} /$ day, days 1-3; dacarbazine $300 \mathrm{mg} / \mathrm{m}^{2} /$ day, days 1-3; ifosfamide $2,500 \mathrm{mg} / \mathrm{m}^{2} /$ day, days $1-3$. Results: Although complete response was not achieved in any of the patients, 4 of the 8 patients showed partial response. The median time to disease progression was 74 days, and the overall median survival was 148 days. Grade 3 or more severe hematological toxicity was encountered in all patients. Conclusion: MAID therapy for metastatic malignant phyllodes tumors and stromal sarcoma was moderately effective in terms of tumor reduction. However, the treatment was associated with severe toxicity.

\author{
Schlüsselwörter \\ Chemotherapie · Phylloidtumor, maligner - Metastasen
}

\section{Zusammenfassung}

Hintergrund: Maligne Phylloidtumoren und Stromasarkome sind seltene Malignome der Brust. Die Wirksamkeit systemischer Chemotherapie bei malignen Phylloidtumoren mit Metastasen und bei Stromasarkomen ist bisher unbekannt. Patienten und Methoden: 8 Patienten mit metastasierten, malignen Phylloidtumoren oder Stromasarkomen, die eine Chemotherapie nach dem MAID-Schema (Mesna, Doxorubicin, Ifosfamid, Dacarbazin) erhalten hatten, wurden retrospektiv untersucht. Die MAID-Therapie wurde alle 4 Wochen folgendermaßen intravenös verabreicht: Mesna $1500 \mathrm{mg} / \mathrm{m}^{2} / \mathrm{Tag}$, Tag 1-4; Doxorubicin 20 mg/m²/Tag, Tag 1-3; Dacarbazin 300 mg/ $\mathrm{m}^{2} / \mathrm{Tag}$, Tag 1-3; Ifosfamid $2500 \mathrm{mg} / \mathrm{m}^{2} / \mathrm{Tag}$, Tag 1-3. Ergebnisse: Obwohl keiner der Patienten vollständig auf die Therapie ansprach, zeigten 4 der 8 Patienten eine Teilreaktion. Die mediane Zeit bis zur Krankheitsprogression betrug 74 Tage, die mediane Gesamtüberlebenszeit 148 Tage. Bei allen Patienten wurde eine schwere hämatologische Toxizität Grad 3 und höher festgestellt. Schlussfolgerung: Zwar hatte die MAID-Chemotherapie bei metastasierten, malignen Phylloidtumoren und Stromasarkomen eine geringfügige Wirkung im Hinblick auf den Rückgang des Tumors, allerdings geht mit der Behandlung eine schwere Toxizität einher.

\begin{tabular}{ll}
\hline KARGER & ○ 2006 S. Karger GmbH, Freiburg \\
$\begin{array}{l}\text { Fax +49 76145207 14 } \\
\begin{array}{l}\text { E-mail Information@Karger.de } \\
\text { www.karger.com }\end{array}\end{array}$ & $\begin{array}{l}\text { Accessible online at: } \\
\text { www.karger.com/brc }\end{array}$
\end{tabular}




\section{Introduction}

Malignant phyllodes tumors (MPT) and stromal sarcoma of the breast are rare tumors, accounting for less than $1 \%$ of all breast tumors, and are frequently associated with distant metastases [1]. The tumors present with similar clinical features, and the most common sites of metastasis are the lungs, liver, bone and skin [2-4]. Metastasis to these sites often occurs in the absence of lymph node involvement [4, 5]. MPT are histopathologically distinguished from true sarcomas by the presence of epithelial elements within the cellular connective tissue stroma. The majority of MPT are positive for estrogen and progesterone receptors [6, 7]. However, functional hormone receptors are probably not present, as response to hormone therapy has not been reported $[4,8,9]$. The role of radiation therapy in the management of MPT has not been clearly addressed in previous reports [9-11]. Systemic therapy of metastatic MPT is based on the principles of sarcoma rather than carcinoma treatment [1].

A variety of combination chemotherapies have been developed for the treatment of metastatic soft tissue sarcoma. A typical regimen consists of doxorubicin with an alkylating agent with or without other agents. MAID therapy (mesna, doxorubicin, ifosfamide, dacarbazine) is an effective regimen which was reported to yield a response rate of $47 \%(10 \%$ complete response) in a large phase II trial on the treatment of metastatic soft tissue sarcoma [12]. A subsequent randomized trial revealed that MAID therapy was associated with a significantly better response rate and time to progression than therapy with doxorubicin and dacarbazine alone [13]. To date, there are no reports on the treatment of MPT and stromal sarcoma of the breast with combination regimens containing ifosfamide and doxorubicin which are active agents against metastatic sarcomas $[12,13]$. This retrospective study summarizes our clinical experience with MAID therapy for patients with metastatic MPT and stromal sarcoma of the breast.

\section{Patients and Methods}

Between 1995 and 2004, 8 consecutive patients with metastatic MPT and stromal sarcoma of the breast were treated with MAID therapy at National Cancer Center Hospital, Tokyo, Japan. The diagnosis was histopathologically confirmed as metastatic MPT in 7 patients, and metastatic stromal sarcoma in 1 patient. None of the patients had previously received systemic chemotherapy or radiation therapy.

MAID therapy was administered intravenously every 4 weeks as follows: mesna $1,500 \mathrm{mg} / \mathrm{m}^{2} /$ day, days $1-4$; doxorubicin $20 \mathrm{mg} / \mathrm{m}^{2} /$ day, days $1-3$; dacarbazine $300 \mathrm{mg} / \mathrm{m}^{2} /$ day, days $1-3$; ifosfamide $2,500 \mathrm{mg} / \mathrm{m}^{2} /$ day, days $1-3$. The therapy was repeated over 6 cycles or until evidence of disease progression, occurrence of unacceptable toxicity or patient refusal. All patients had bidimensionally measurable lesions, and the responses were objectively evaluated according to WHO criteria [14]. Toxicity was scored according to the National Cancer Institute Common Toxicity Criteria (NCI-CTC ver 2.0). Time to progression was measured from the first day of treatment until evidence of disease progression or until the last day of the follow-up period without disease progression. Overall survival was
Table 1. Patient characteristics

\begin{tabular}{ll}
\hline Patients, $\mathrm{n}$ & 8 \\
Median age (range), years & $53(33-61)$ \\
Performance status, $\mathrm{n}$ & \\
1 & 5 \\
2 & 2 \\
3 & 0 \\
4 & 1 \\
Histology, n & \\
Malignant phyllodes tumor & 7 \\
Stromal sarcoma & 1 \\
Side of primary lesion, $\mathrm{n}$ & \\
$\quad$ Right & 3 \\
Left & 5 \\
Time to systemic recurrence after & 278 \\
primary surgery (range), days & $(32-848)$ \\
Disease sites, $\mathrm{n}$ & \\
Lung metastasis & 8 \\
Pleural effusion & 4 \\
Soft tissue metastasis & 4 \\
Bone metastasis & 3 \\
Peritoneal dissemination & 2 \\
Liver metastasis & 1 \\
\hline
\end{tabular}

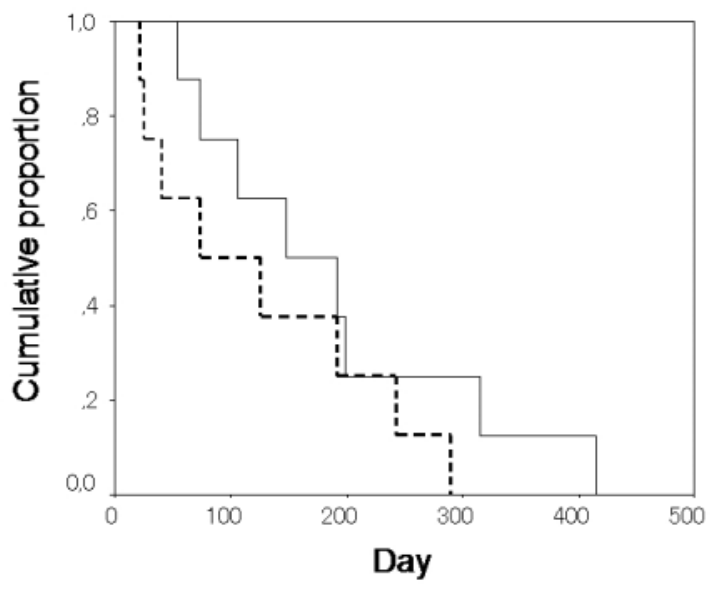

Fig. 1. Kaplan-Meier analysis of time to progression (dotted line) and the overall survival (solid line)

measured from the first day of treatment until death or the last day of the follow-up period. The median time to progression and median overall survival were estimated by the Kaplan-Meier method using the SPSS 11.0J software (SPSS Inc. Chicago, IL, USA).

\section{Results}

The patient characteristics are summarized in table 1 . The median patient age was 53 years (range: 33-61), and the median time to systemic recurrence after primary surgery was 278 days (range: 32-848). None of the patients had received any adjuvant chemotherapy. The median number of organs showing metastasis was 3 (range: 1-6), and all patients had multiple lung metastases. 
Fig. 2. A Metastatic malignant phyllodes tumor in 33-year-old woman. Computed tomography scan showed multiple huge pleural metastases on the right hand side, causing a shift of the mediastinum to the left.

B Disappearance of the pleural metastases after completion of 6 cycles of MAID therapy. Nonetheless, the patient suddenly died of brain hemorrhage due to brain metastases without any evidence of extracranial recurrence.
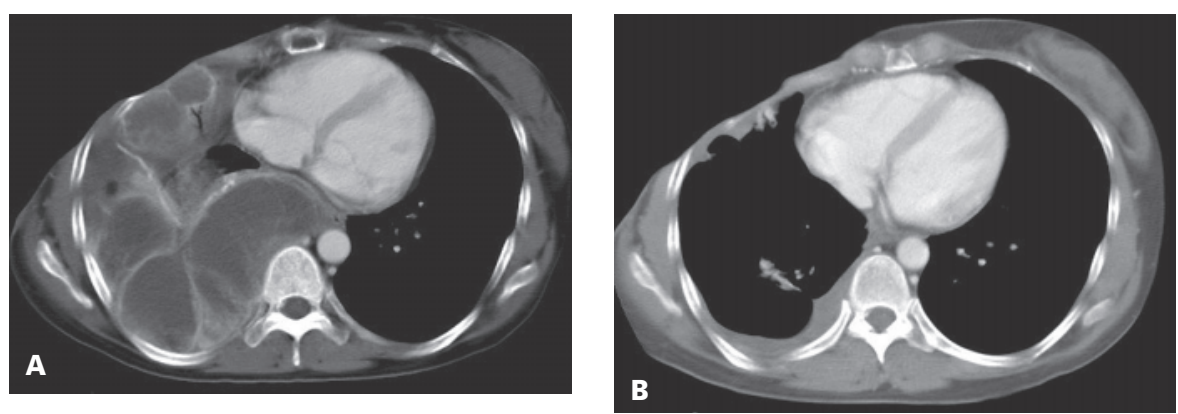

The median number of treatment cycles was 4 (1-6). The mean doxorubicin dose was $230 \mathrm{mg} / \mathrm{m}^{2}$ (range: 60-360). All patients had measurable lesions before the start of treatment. Complete response was not achieved in any of the patients, however, 4 patients showed partial response. 2 patients showed stable disease and 2 patients progressive disease. Patients with partial response showed clear clinical benefit regarding the required dose of opioid agents and/or oxygen therapy. The median time to progression was 74 days (range: 21-290), and the median survival time was 148 days (range: 54-415) (fig. 1). The median interval from diagnosis to death was 598 days (range: 286-1,257). After achieving partial response (fig. 2), 3 patients showed disease progression with the emergence of brain metastasis. As a consequence, 1 patient died from brain hemorrhage after the completion of MAID therapy. 2 patients with progressive disease were treated with radiotherapy for bone metastasis and whole-brain radiotherapy, respectively. Only 1 patient received 2 additional courses of MAID therapy as second-line therapy, but the clinical response remained unchanged. Although the combination regimen of docetaxel $\left(60 \mathrm{mg} / \mathrm{m}^{2}\right.$, day 8$)$ plus fixed dose rate infusion of gemcitabine $\left(800 \mathrm{mg} / \mathrm{m}^{2}, 10 \mathrm{mg} / \mathrm{min}\right.$, days 1 and 8$)$ was administered as third-line chemotherapy, this patient showed evidence of progression in the form of skin metastasis during the first course.

Hematological toxicity constituted the major toxicity. 7 patients developed grade 3 or more severe neutropenia, including 5 patients with febrile neutropenia requiring hospitalization and 4 patients requiring administration of the granulocyte colony-stimulating factor (G-CSF). Grade 3 or more severe anemia was observed in 3 patients. Dose reduction was required in 1 patient due to anemia. However, there were no treatment-related deaths. Gastrointestinal toxicity was the most common toxicity but did not reach grade 3 or more in any of the patients. All patients developed complete alopecia. Clinically detectable renal toxicity, cardiotoxicity or hematuria were not seen.

\section{Discussion}

Metastatic MPT and stromal sarcoma of the breast have a poor prognosis, and the average interval from diagnosis to death in patients with metastasis has been reported to be 30 months [4]. Systemic therapy is based on principles of treatment for sarcoma rather than carcinoma of the breast [1]. In our study, MAID therapy yielded a favorable response, but most patients developed febrile neutropenia requiring administration of G-CSF. Thus, this therapy appears to be more toxic than single-agent or double-agent therapies with doxorubicin and ifosfamide. 3 of the 4 patients who showed partial response subsequently developed brain metastasis, although the objective tumor showed excellent response close to complete remission. The MAID therapy may not be effective for intracranial lesions because of the blood-brain barrier. Thus, progression with development of brain metastasis should be watched out for in patients showing good response and in whom a long disease-free interval is expected.

Although time to progression and survival time of the patients treated with the MAID therapy in this study were shorter than in previous case reports, patients showed improvement of clinical symptoms along with tumor response. Therefore, combination chemotherapy with the MAID therapy containing doxorubicin and ifosfamide may be indicated for patients with rapidly progressive disease or severe symptoms. In patients with poor performance status or other complications, the combination of doxorubicin and ifosfamide might be better than MAID therapy in terms of toxicity.

The rarity of metastatic MPT and sarcoma of the breast makes it difficult to conduct clinical trials for these conditions. Therefore, an optimal systemic chemotherapy has not yet been defined, and only a small number of case reports have described a tumor response to cytotoxic drugs. Doxorubicin and dacarbazine used as single agents have yielded no satisfactory response $[9,10]$, but their administration in combination with cisplatin has been reported to be effective [15]. Treatment with ifosfamide administered as a single agent was reported by one study to be associated with favorable response in 2 of 3 patients, and these 2 patients showed complete response that lasted for 26 and over 61 months, respectively [16]. Burton et al. [9] described chemotherapy with cisplatin and etoposide, and reported partial response in 2 of 3 patients. Although several studies have reported variable expression levels of estrogen and progesterone receptors, the effectiveness of endocrine therapy has not been reported in either the adjuvant or the palliative setting $[6,7,9,17]$. Although MAID therapy 
demonstrated moderate efficacy in this small number of patients, the treatment was associated with severe toxicities. Therefore, less toxic systemic chemotherapy must be explored for patients with metastatic MPT, and the biology of the tumors needs to be clarified in further detail to develop strategies to improve the clinical benefits of treatment, including prolongation of survival in patients with metastatic MPT of the breast.

\section{Acknowledgment}

The authors thank Dr. Mamoru Fukuda and Dr. Ichiro Maeda (St. Marianna University, Kawasaki, Japan), Dr. Seigo Nakamura and Dr. Katsutoshi Enokido (St Luke's International Hospital, Tokyo, Japan), Dr. Yasuko Uchida (Saiseikai Kurihashi Hospital, Saitama, Japan), Dr. Noriyuki Baba (Tokyo Kyosai Hospital, Japan), Dr. Toshihiro Kai (Omiya Medical Center, Jichi Medical School, Tochigi, Japan), and Dr. Hidetaka Kawabata (JR Tokyo General Hospital, Japan) for their assistance.

\section{References}

1 Anderson BO, Lawton TJ, Lehman CD, Moe RE: Phyllodes tumor; in Harris JR, Lippman ME, Morrow M, Osborne CK (eds): Diseases of the Breast, ed 3, Philadelphia, Lippincott-Williams and Wilkins, 2004, pp 991-1006.

2 McGregor GI, Knowling MA, Este FA: Sarcoma and cystosarcoma phyllodes tumors of the breast: a retrospective review of 58 cases. Am J Surg 1994; 167:477-480.

3 Reinfuss M, Mitus J, Smolak K Stelmach A: Malignant phyllodes tumors of the breast: a clinical and pathological analysis of 55 cases. Eur J Cancer 1993;29A:1252-1256.

4 Kessinger A, Foley JF, Lemon HM, Miller DM: Metastatic cystosarcoma phyllodes: a case report and review of the literature. J Surg Oncol 1972;4: 131-147.

5 Zissis C, Apostolikas N, Konstantinidou A, Griniatsos J, Vassilopoulos PP: The extent of surgery and prognosis of patients with phyllodes tumor of the breast. Breast Cancer Res Treat 1998;48:205-210.

6 Brentani MM, Nagai MA, Oshima CT, Pacheco MM, Goes JC, Lemos LB: Steroid receptor in cystosacoma phyllodes. Cancer Detect Prev 1982;2: 211-219.
Rao BR, Meyer JS, Fry CG: Most cystsarcoma phyllodes and fibroadenomas have progesterone receptor but lack estrogen receptor: stromal localization of progesterone receptor. Cancer 1981;47: 2016-2021.

8 Kesterson GH, Georgiade N, Seigler HF, Barton TK, McCarty KS Sr, McCarty KS Jr: Cystosarcoma phyllodes: a steroid receptor and ultrastructure analysis. Ann Surg 1979;190:640-647.

-9 Burton GV, Lowell LH, Leight GS, Iglehart JD, McCarty KS, Cox EB: Cystosarcoma phyllodes: effective therapy with cisplatin and etoposide chemotherapy. Cancer 1989;63:2088-2092.

10 Contarini O, Urdaneta LF, Hagan W, Stephenson SE: Cystosarcoma phylodes of the breast: a new therapeutic proposal. Am Surg 1982;48:157-166.

11 Turalba CIC, El-Mahdi AM, Ladaga L: Fatal metastatic cystosarcoma phyllodes in an adolescent female: case report and review of treatment approach. J Surg Oncol 1986;33:176-181.

12 Elias A, Ryan L, Sulkes A, Collins J, Aisner J, Antman KH: Response to mesna, doxorubicin, ifosfamide, and dacarbazine in 108 patients with metastatic or unresectable sarcoma and no prior chemotherapy. J Clin Oncol 1989;7:1208-1216.
3 Antman K, Crowley J, Balcerzak SP, Rivkin SE, Weiss GR, Elias A, Natale RB, Cooper RM, Barlogie B, Trump DL, Doroshow JH, Aisner J, Pugh RP, Weiss RB, Cooper BA, Clamond GH, Baker LH: An intergroup phase III randomized study of doxorubicin and dacarbazine with or without ifosfamide and mesna in advanced soft tissue and bone sarcomas. J Clin Oncol 1993;11:1276-1285.

14 Miller AB, Hoogstraten B, Staquet M: Reporting results of cancer treatment. Cancer 1981;147: 207-214.

15 Allen R, Nixon D, York M, Coleman J: Successful chemotherapy for cystosarcoma phyllodes in a young woman. Arch Intern Med 1985;145: 1127-1128.

16 Hawkins RE, Schofield JB, Withshaw E, Fisher C, Mckinna JA: Ifosfamide is an active drug for chemotherapy of metastatic cystosarcoma phyllodes. Cancer 1992;69:2271-2275.

17 Tse GM, Lee CS, Kung FY, Scolyer RA, Law BK Lau TS, Putti TC: Hormonal receptors expression in epithelial cells of mammary phyllodes tumors correlates with pathologic grade of the tumor: a multicenter study of 143 cases. Am J Clin Pathol 2002;118:522-526. 